Revue d'histoire de l'Amérique française

REYUE D.HISTOIRE DE L'AMÉRIQUE FRANÇAISE

\title{
ANGERS, François-Albert, Pour orienter nos libertés. Fides, Collection Bibliographique économique et sociale, 1969. Préface de Richard Arès, s.j., 9-17 p. et 280 p. \$5.00.
}

\section{Fernand Dumont}

Volume 24, numéro 4, mars 1971

URI : https://id.erudit.org/iderudit/303022ar

DOI : https://doi.org/10.7202/303022ar

Aller au sommaire du numéro

Éditeur(s)

Institut d'histoire de l'Amérique française

ISSN

0035-2357 (imprimé)

1492-1383 (numérique)

Découvrir la revue

Citer ce compte rendu

Dumont, F. (1971). Compte rendu de [ANGERS, François-Albert, Pour orienter nos libertés. Fides, Collection Bibliographique économique et sociale, 1969.

Préface de Richard Arès, s.j., 9-17 p. et 280 p. \$5.00.] Revue d'histoire de

l'Amérique française, 24(4), 597-598. https://doi.org/10.7202/303022ar d'utilisation que vous pouvez consulter en ligne.

https://apropos.erudit.org/fr/usagers/politique-dutilisation/ 


\section{COMPTES RENDUS}

ANGERs, François-Albert, Pour orienter nos libertés. Fides, Collection Bibliographique économique et sociale, 1969. Préface de Richard Arès, s.j., 9-17 p. et 280 p. $\$ 5.00$.

On sait quelle contribution décisive François-Albert Angers a apporté au développement de la recherche et de l'enseignement de la science économique en notre pays. Ses publications techniques, les initiatives diverses qu'il a suscitées auraient suffi déjà à bien remplir la carrière d'un savant très laborieux. Pourtant, Angers a poursuivi en parallèle une autre carrière, aussi chargée que la première, vouée à l'engagement social et national. Le livre dont il est ici question rassemble des textes qui témoignent de cet engagement dans divers domaines: l'éducation, l'économique, le national, la constitution. Le choix est excellent, mais il constitue avant tout une sorte de symbole: la masse énorme des écrits du militant Angers ne saurait être résumée dans ces quelques prélèvements.

Le livre est précieux à plusieurs égards.

Il témoigne d'abord d'une tradition du nationalisme québécois, et particulièrement pour une période où il n'était guère à la mode de s'y rattacher. Un article de 1941, ici reproduit, nous donne quelque idée du climat du temps. Un $\mathrm{M}$. Gravel prétend alors que les gens désireux de retarder l'enseignement de l'anglais jusqu'à la $5^{e}$ année "ne réalisent (sic) pas notre situation économique" et que, si cette position était entérinée, "les nôtres ne pourront plus gagner leur vie, faute de connaître suffisamment l'anglais pour se faire comprendre de leur contremaître". Lointain épisode dans l'éternelle querelle à propos du "français langue de travail". A l'époque déjà, Angers formulait là-dessus des réflexions pleines de sens. Il a eu de la suite dans les idées: trente ans plus tard, on le retrouvera au premier rang du Front du Québec français.

Mais c'est sur l'ensemble des conceptions nationalistes d'Angers que ce livre est révélateur. Je retiens ces lignes: l'homme "a besoin, pour son équilibre psychique, de se sentir intégré - non pas dans une vague humanité - mais bien dans un groupe proche de lui, qui lui ressemble, et dans lequel il peut se reconnaître et se retrouver. Son premier besoin, c'est de pouvoir aimer ce groupe, de pouvoir en être fier pour ce qu'il vaut, quitte à en voir plus tard les déficiences et à vouloir les corriger, justement parce qu'il l'aime (...) Il faut donc que nos écoles, les petites comme les grandes, et nos maîtres, même s'ils sont doctes professeurs d'université, prennent parti sur cette exigence minimale. Mais prendre parti sur quoi ? Pour le patriotisme, bien sûr ! Mais sur quel patriotisme? Voilà bien notre tragédie de peuple soumis à une conquête, et englobé par trop volontairement dans une structure politique complexe, dont il ne sait pas encore se servir, parce que, 
ne l'ayant pas faite lui-même, il ne la comprend pas. Trop de nos éducateurs ne savent plus, par conviction solide, où situer en raison notre patriotisme, et les avatars de deux siècles d'occupation ont plus ou moins embrouillé notre cœur." N'est-ce point le bon sens même ? Nous expliquera-t-on jamais comment on a pu qualifier de fanatique un homme dont ce livre, à toutes les pages, révèle le souci de l'analyse et le sens de la mesure ?

Elles disent aussi sa faculté d'ouverture et d'accueil. Rien de lénifiant chez ce lutteur qui fut avant tout soucieux - pour reprendre une délicieuse expression qui revient quelquefois sous sa plume - d' "ébrancher les questions". Mais il affronte avec droiture, franchise et respect. Ceux dont les options sociales se rangent plus à gauche ne liront pas sans une émotion semblable à la mienne les pages intitulées: "Pourquoi nous diviser ?" Il veut dire: entre nationalistes... "La thèse qui voudrait prétendre, écrit-il, que les nationalistes dits de gauche ne peuvent pas être des vrais nationalistes, à cause du caractère antinational de l'idéologie socialiste traditionnelle, reste purement verbale." Il plaide pour la diversité en y voyant un signe de santé.

Angers "homme de droite" ? La légende le veut. Ma foi à faire l'histoire, à parcourir les textes qui nous sont ici offerts, on aura du mal à s'en tenir à une aussi commode catégonitie. Jé né vois pas queis pouvoirs et quels intérêts établis pourraient y trouver la moindre caution. Angers se méfie des nationalisations, mais il plaide pour les coopératives et pour une décentralisation de la propriété des moyens de production. S'il n'utilise guère le mot à la mode de "participation", l'idée est partout présente comme un thème central de sa pensée. Il plaide pour l'humanisme classique mais demande qu'on fasse une place également essentielle aux mathématiques... Et s'il faut passer des idées au vocabulaire, je ne me retiendrai pas de citer ce passage: "S'il était vrai que les ouvriers se voient refuser les seules situations inférieures qu'ils sont en mesure d'occuper, qu'ils sont ostracisés (le mot est exact parce qu'ils n'ont nul besoin de l'anglais pour effectuer leur besogne) à cause d'une connaissance insuffisante de l'anglais, eh bien ! je dirais que ce n'est pas le temps d'apprendre l'anglais, c'est le temps de faire une révolution."

Le nationalisme est tradition vivante. Celui de ma génération ne s'identifie pas à celui d'Angers. Mais je vois bien à lire ce livre qu'il en procède, comme de celui de Groulx dont il fut le frère d'armes. C'est à nous ses cadets et aux plus jeunes encore qu'il s'adresse sans doute quand il écrit: "Peut-être ceux qui ne sont pas prêts à se ranger sous la bannière de Mgr Pâquet accepteront-ils de marcher derrière celle de Bernanos, qui a dit: "L'honneur pour un peuple n'est pas de vaincre, mais de survivre, coûte que coûte, jusqu'au jour certain, inéluctable, où Dieu doit triompher à sa place." Cet honneur-là, Angers en a fait l'inspiration de son immense labeur. Est-il nécessaire de lui assurer que, pour bien des hommes qui sont aujourd'hui dans la quarantaine, la leçon n'a pas été perdue?

Institut supérieur des sciences humaines

FERNAND Dumont Université Laval 